\title{
A Methodology for Addressing the Second-Level Digital Divide \\ A Practical Experience
}

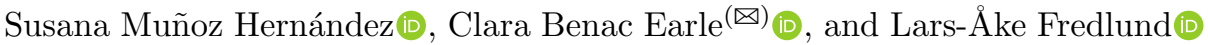 \\ Universidad Politécnica de Madrid, Madrid, Spain \\ \{susana, cbenac, lfredlund\}@fi.upm.es \\ http://ww. techpeople.care
}

\begin{abstract}
In this article we describe a methodology, and its evaluation, for achieving technical competence through digital literacy training using self-learning training material. The key component is self-learning in the sense that the targeted population learns digital operational skills without the need of a teacher. This is achieved through the adaptation of the training material to the trained group. As training groups are diverse, e.g., including both populations in developing and developed countries, and varying in age aspects, gender, languages, literacy levels and technological literacy levels, materials and the speed which training takes place has to be adapted to take into account these differences. The methodology involves use of training videos, and use a dual screen approach where training material is shown on one screen and training takes place on a second screen (computer). The approach has been evaluated in both developing countries and developed countries, with training groups of different capabilities and backgrounds (in Kenya, El Salvador, Spain, France and The Netherlands), with promising results.
\end{abstract}

Keywords: Digital literacy training $\cdot$ Localisation $\cdot$ Individual training $\cdot$ e-learning $\cdot$ Digital skills acquisition

\section{Introduction}

Since the 1990s, the digital divide [14] has been defined as the inequalities in access to and use of Information and Communication Technologies (ICTs), mostly the Internet [3]. Initially, the study of the digital divide observed the distinction between those who had access to the internet and those who had not. This is called the first-level digital device. Regarding the first-level digital divide, there is a clear divide among developed countries, where the majority of the population has internet access, to less developed countries where, although the internet access is constantly growing, there are still large parts of the population that do not have easy access to the internet.

Supported by the "e-Health inclusion through ICT training" project funded by EITHealth.

(C) IFIP International Federation for Information Processing 2020

Published by Springer Nature Switzerland AG 2020

M. Hattingh et al. (Eds.): I3E 2020, LNCS 12067, pp. 331-337, 2020.

https://doi.org/10.1007/978-3-030-45002-1_28 
Later, the second-level digital divide mostly focuses on digital skills [5]. Researchers on digital skills distinguish between technical competence or operational skills, i. e., skills like using a mouse or a keyboard, information literacy, which is "the ability to recognise when information can solve a problem or fill a need and to effectively employ information resources". Additionally, Scheerder et al. [12], distinguished "information navigation skills" (the ability to find, select, and evaluate sources of information on the Internet), "social skills" (the ability to use online communication and interactions to understand and exchange meaning and acquire social capital) and "creative skills" (needed to create different types of content and to publish or share this with others on the Internet).

The second-level digital divide, in particular, operational skills, is an important social issue both in developing countries an in developed countries. In developing countries, young people need to have certain skills (for example, effective use of text editors and spreadsheets) in order to get a better job. In developed countries, society is clearly becoming more digital, providing many new digital services, some for very basic services like to get a doctor appointment, at a fast pace. Unfortunately, the most vulnerable people are often left behind. Many seniors, migrants and minorities are suffering social exclusion due to their lack of digital literacy, Thus, large segments of the population lacks the necessary skills to interact effectively with such digitalized services

To address the second-level digital divide, in particular, operational skills, the usual approach to train the population, both in developing and developed countries, involves face-to-face training with teachers, since the usual training material (MOOCS, etc.) is not suitable for those without the most basic digital skills. However, often such face-to-face training activities has limited effectiveness. The typical training in groups has many problems: logistics (participants with different time availability) and pedagogical (participants with different learning speed) problems, and teachers are sometimes ill-equipped to deal with individuals not only experiencing digital illiteracy but also experiencing low literacy in general. Of course, there are many qualified teachers but, in general, scaling such face-to-face training activities to be able to train big sectors of a population is very costly in terms of the human resources needed; in general it is simply not a sustainable activity. In addition when the trainees are located in rural or remote areas the human resources needed (teachers) may not be available in sufficient quantities. In developing countries typically both problems occur, i.e., too high training costs, and limited availability of qualified teachers.

To address these issues, we have developed a methodology that relies on self-learning, i. e., training without the need of teachers [6,13]. Given such a methodology, we formulate the following research question - can the methodology be applied with success both in developing and developed countries? To answer this research question, we have conducted a series of training activities in both developing countries, e.g., Kenya and El Salvador, and developed countries such as Spain, France and The Netherlands.

The rest of the paper is organised as follows: in Sect. 2 a summary of the characteristics of the methodology is presented. Next, Sect. 3 describes the 
evaluation of the methodology in the aforementioned countries, and Sect. 4 summarises the results, discusses the work, and presents plans for the future.

\section{Methodology}

In this section, we summarise the key ingredients of our methodology which is in essence based on e-learning and self-learning concepts [8-10], and which does not require trained teachers to assist trainees.

No teachers: The methodology does not require a trained teacher to assist trainees. In the practical studies we have conducted (see Sect. 3) assuring that the practical necessities for conducting the literacy training (e.g., availability of working computers, access to literacy training material) are met is the responsibility of a local training coordinator, who does not need to be familiar with the literacy training material.

Use of a two-screen approach: The methodology follows a learning-by-doing approach where the trainee is presented with two screens: (i) one, typically a tablet, where the training material, a number of videos, is shown and (ii) a second one, typically a desktop computer, used by the trainee to practice the practical exercises shown in the first screen. The benefits of using dual screens has been studied in a number of works, e.g., [4,7].

Adapting training material to the trained group: When training diverse populations the training material used should be localised, e.g., in general with respect to languages utilised, with respect to literacy levels, etc. In general such a localisation (e.g., in the website domain [11]) process typically consists of a translation to a language and a cultural adaptation. In our methodology, both the language used for instructions, and the video speed, is adapted to the trained groups: (i) Language adaptation: normally the videos are in the native language of the trainees. However, in the case of migrants, they may choose to either receive instructions in their native language or in the language of the country they currently reside; (ii) Age adaptation: for instance, the speed of the videos is slower for elderly people than for younger people; (iii) Literacy adaptation: for instance, the language in the video is "simpler" for people with low literacy than for other with higher levels of literacy; (iv) Gender adaptation, for instance, we use inclusive language;

(v) Technology literacy adaptation: for many trainees the use of our training setup comprising tablets and desktop computers can be their first contact with such technological equipment; we have extensive experiences with adapting training material with regards to such concerns.

As an example, in the training of young women in Kenya with reduced school experience, the videos played rapidly, but the language used was simplified, and adapted to their gender, and level of technological literacy.

Use of specially developed software training applications: We have developed a number of new software training applications to ensure that the interactions with the training application is intuitive, providing a controlled environment specifically adapted to users without digital background. 


\section{Evaluation}

In this section we summarise the studies (Fig.1) that have been used for evaluation: Lamu (Kenya), Tecoluca (El Salvador), and a study in the context of a EIT-Health project with sessions in Spain, France and The Netherlands.
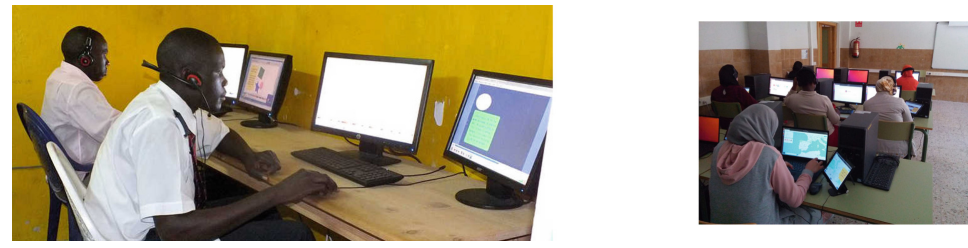

Fig. 1. Digital literacy training in Lamu, Kenya (left), and Madrid region, Spain (right)

\subsection{The Lamu Study}

A report on a first experience (from 2011) applying this methodology in Lamu at the northeast of Kenya is given in [13]. The Digital Opportunities project [2] dealt with the digital literacy of a target group of young people who wanted to improve their chances of getting a job by acquiring some basic computing skills such as using word processors, web browsing, working with spreadsheets, etc. Interestingly, they had already attended local private IT courses teaching e.g. basic word processor tools skills, and had even received a diploma. However, in these courses, the students would typically just observe the teacher demonstrating an application, without the students getting a chance to experiment themselves.

Evaluation. Most of the students had previous training in the subject matter but when their skill level was evaluated through a practical exam before the start of the course, it was found to be poor. In total 86 students attended our training, and passed a final exam which evaluated that their skills were at a satisfactory level. Of these 86 students, 39 answered a questionnaire after the course, regarding what skill level (from 0 to 10) in the subject matter that they then perceived themselves to possess before the course, as well as after the course. The results was an average perceived skill level of 2.5 before the course, and 8.5 after having taken the course. That is, the students considered that the course had greatly improved their operational skills.

\subsection{The Tecoluca Study}

Another training experience using our methodology took place in Tecoluca, El Salvador, during 2016-2017. The goal of the PALDICA project was the digital 
training of adults, with a particular focus towards the digital service needs and interests of adult farmers, in particular, acquiring basic operational skills (for instance, how to use the mouse and the keyboard), basic use of a word processor and basic email and internet browsing. The training was to take place at centers funded by an international cooperation agency.

Evaluation. In this project, the training material was developed (localised) and first used in a pilot project where the coordinators of the centers were trained, before they were due to assist the target population in their training. This prior training activity had not been planned, and indeed was not strictly needed from the point-of-view of the training methodology. However, in practice it was deemed necessary to ensure that the training coordinators were sufficiently motivated to assist in future training activities. 7 coordinators took part in this pilot projects, and two of them filled in a written questionnaire stating that the training had greatly improved their operational skills. Unfortunately, at that moment the funding of the centers where the training was to have taken place ceased, and the centers were closed. The more large-scale training of adult farmers that we had planned for could not take place. On the positive side, we gained new insights from developing further, and localising, the training material, and moreover we came to appreciate the financial difficulties of conducting such training activities.

\subsection{The EIT-Health Study}

Recently, we have continued the development of the training methodology and platform, and its evaluation, in the context of a European project oriented to the digital inclusion of European seniors and migrants, "e-Health inclusion through ICT training" (eHi-ICTT) funded by EIT-health [1], which ended on December 31st, 2019. The project focused specifically on helping its target audience (senior people including migrants) to be able to access e-health services. The partners in the project were: (i) SERMAS, the public health service of the Madrid region. (ii) E-seniors, a French association which provides ICT classes to seniors. (iii) Leyden academy, a knowledge institute in the Netherlands, which conducts scientific research on various topics focused upon vitality and ageing; (iv) Universidad Politécnica de Madrid (the university of the article authors).

Evaluation. The project had the following main activities: (i) definition of training contents, including the collaborative process with project participants to obtain the agreed upon training program for each collective; (ii) development of the audiovisual material; (iii) conducting training session to evaluate the success of the approach. The results were measured as follows. First, a pre-questionnaire was created to measure the operational skills owned by the target population before taking the course. Secondly, a post-questionnaire was designed to measure the acquisition of the same skills after taking the course. In Madrid, a group of 42 Arab migrants and 28 seniors attended the training; in Pairs 26 seniors; and 28 Arab migrants in The Netherlands. We are still analysing the detailed results, 
but the informal feedback we have received has been very positive, with several participants for instance telling us that they were able for the first time to make an appointment with a doctor using an online system. A detailed analysis showing to what extent the goals of the project has been met, through measuring the outcome of the training sessions (e.g., to what extent trainees can successfully use medical digital systems), will be presented in a future article.

\section{Conclusions and Future Work}

In this paper, we have presented the key characteristics of our self learning based methodology to address the second-level digital divide with regards to operational skills. The approach works with specially developed software training applications, and uses a two-screen approach. The methodology has been applied in a number of training events in Kenya, El Salvador, and Europe. In all locations students reported an improvement in their operational skills due to the training. Based on these findings, we are now working on reducing the amount of work needed to adapt the overall methodology to different contexts, e.g., to account for differences in language, gender, literacy, etc.

We believe that our methodology holds great promise, and future plans include demonstrating its potential for training on a significantly larger scale. Moreover, we are eager to cooperate with other institutions that share the ambition of reducing the second-level digital divide.

\section{References}

1. https://www.eithealth.eu/

2. Digopps, digital opportunities project. https://digopps.wixsite.com/digitaloppor tunities

3. Castells, M.: The Internet Galaxy: Reflections on the Internet, Business, and Society. Oxford University Press on Demand, Oxford (2002)

4. Colvin, J., Tobler, N., Anderson, J.: Productivity and multi-screen computer displays. Rocky Mt. Commun. Rev. 2, 31-53 (2004)

5. Hargittai, E.: Second-level digital divide: differences in people's online skills. First Monday 7(4) (2002)

6. Hernandez, S.M.: Looking for sustainable software for education in developing countries. In: 2014 IEEE Global Engineering Education Conference, EDUCON 2014, Istanbul, Turkey, 3-5 April 2014, pp. 1108-1111. IEEE (2014)

7. Hsu, J.-M., Chang, T.-W., Yu, P.-T.: Learning effectiveness and cognitive loads in instructional materials of programming language on single and dual screens. Turk. Online J. Educ. Technol. 11, 156-166 (2012)

8. Mayer, R.E.: Cognitive Theory of Multimedia Learning. Cambridge Handbooks in Psychology, pp. 31-48. Cambridge University Press, Cambridge (2005)

9. Mitra, S., Khas, H.: Minimally invasive education for mass computer literacy. CSI Commun. 32, 1216 (1999)

10. Mohammadyari, S., Singh, H.: Understanding the effect of e-learning on individual performance: the role of digital literacy. Comput. Educ. 82, 11-25 (2015) 
11. Pym, A.: Website localizations. In: Malmkjær, K., Windle, K. (eds.) The Oxford Handbook of Translation Studies. Oxford University Press, Oxford $(2011,2013)$

12. Scheerder, A.J., van Deursen, A., van Dijk, J.: Determinants of internet skills, uses and outcomes. A systematic review of the second- and third-level digital divide. Telem. Inf. 34(8), 1607-1624 (2017)

13. Silvestre, M., Munoz, S., Rubio, M.A.: A successful entrepreneurship formula for solving computer illiteracy. In: IEEE Global Humanitarian Technology Conference, GHTC 2014, USA, October 2014. IEEE (2014)

14. Srinuan, C., Bohlin, E.: Understanding the digital divide: a literature survey and ways forward. In: Innovative ICT Applications - Emerging Regulatory, Economic and Policy Issues 52191, International Telecommunications Society (ITS) (2011) 